\title{
Mario Santiago Jiménez y Denisse de Jesús Cejudo Ramos (coords.), Revisitando el movimiento estudiantil de 1968. La historia contemporánea y del tiempo presente en México, México, Universidad Nacional Autónoma de México, 2018, 166 páginas.
}

Aníbal Pacheco Salazar ${ }^{1}$

Editor: Sergio Paolo Solano. Universidad de Cartagena-Colombia.

Copyright: $\odot$ 2021. Corredor, M. Este es un documento de acceso abierto, distribuido bajo los términos de la licencia https://creativecommons.org/licenses/by-ncsa/4.0/ la cual permite el uso sin restricciones, distribución y reproducción en cualquier medio, siempre y cuando que el original, el autor y la fuente sean acreditados.

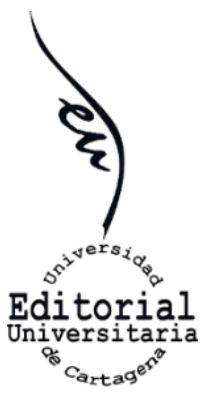

Los libros que tienen por objetivo dar una explicación del movimiento estudiantil ocurrido en la Ciudad de México, a finales de 1968, son sumamente abundantes, sin embargo, un gran porcentaje de ellos fueron elaborados por periodistas o tienen tintes testimoniales; es por ello que los historiadores siguen explorando los archivos y reformulando las preguntas en torno a un fenómeno capital en la historia mexicana del siglo XX. Al cumplirse medio siglo de la "Masacre de Tlatelolco" como comúnmente se le ha denominado, los autores lanzan un reto al gremio para repensar las dimensiones del suceso antedicho y reflexionar sobre su unicidad, espontaneidad y, ante todo, su impacto en el desarrollo de la vida pública de la nación.

En virtud de lo anterior, la obra dista de narrar minuciosamente los acontecimientos de forma cronológica, y mucho menos ofrece respuestas decisivas y determinantes, todo lo contrario. A pesar de que el epicentro de la discusión es el movimiento estudiantil, es éste un pretexto para elaborar nuevos cuestionamientos, reconocer actores inéditos, e identificar aquellos puntos de inflexión que han sido tradicionalmente considerados como parteaguas en la historia reciente del país.

Es preciso decir que el libro es resultado de las discusiones llevadas a cabo por un conjunto de académicos durante más de tres años, y que coincidieron en la necesidad de discurrir en torno a las interpretaciones de hechos "recientes". De ahí que el ejemplar esté compuesto por cinco capítulos, cada uno es producto de la investigación, pero sobre todo de las meditaciones de un investigador diferente.

El primer apartado funciona como una clave para poder descifrar los cuatro subsiguientes pues los une y les da sentido. En él, tanto Mario Santiago como Denisse de Jesús Cejudo - coordinadores de la obra - manifestaron su interés por la historia del tiempo presente, así como la importancia de que los investigadores jóvenes se acerquen a su estudio. Por lo mismo, sostienen que las manifestaciones estudiantiles acaecidas a finales de los sesenta del siglo XX son un excelente motivo para cuestionar la inalterabilidad de los lugares comunes en la periodización historiográfica, así como los relatos consensuados. Tales problemas son inherentes a cualquier objeto de estudio sin importar su distancia

${ }^{1}$ Licenciado en Historia, Universidad Nacional Autónoma de México. Maestría en Historia Moderna y Contemporánea Instituto de Investigaciones Dr. José María Luis Mora. 
en el tiempo, pero son mucho más palpables en aquellos sucesos que fueron vividos, narrados y analizados a la vez.

Los autores parten de que toda historia es pensada y escrita desde el presente que, al ser mudable, admite reformulaciones constantes así como diálogo permanente con apreciaciones precedentes. En el caso que atañe al libro, se apuesta por la interdisciplina como el camino más viable para acercarse a un objeto de estudio tan intrincado, aunque dicha operación conlleva el problema de la definición, es decir, identificar cuál es la particularidad de la historiografía en las interpretaciones emitidas en conjunto.

Como respuesta, los escritores señalan que las explicaciones propias del historiador deben considerar que, si bien los cortes temporales se dan en función de los procesos, obedecen primordialmente al sujeto que los establece y analiza. En otras palabras, señalar un inicio y un final es responsabilidad de la persona que observa los hechos, más que de los actores que participaron en ellos. No obstante, cuando se trata de acontecimientos tan cercanos es común que la memoria y el análisis académico se fundan en un solo relato, que es guiado por premisas hechas antes de la indagación.

A decir de Mario Santiago y Denisse de Jesús Cejudo, esta es la razón por la que los trabajos posteriores a la década de los sesenta han visto como parteaguas a la Revolución mexicana y de ahí den un salto hasta 1968, al calificarlas como fechas trascendentales en el siglo XX mexicano, y no solo eso, pareciera que la Universidad Nacional Autónoma de México y el Instituto Politécnico Nacional eran las únicas instituciones en pie de lucha, generadoras de miles de estudiantes politizados — con tintes izquierdistas - y que la capital del país fue el único espacio geográfico en donde se las masas expresaron sus inconformidades. En esencia, contra estos supuestos inalterables es que hay que luchar, y el presente libro es una invitación a hacerlo.

El segundo capítulo corrió a cargo de Carmen Collado, quien hizo un análisis de las interpretaciones llevadas a cabo por investigadores, periodistas y actores del movimiento, pertenecientes a dos grupos de edad diferentes, a saber: la mitad creció en la época de la posguerra, nacidos entre 1946 y 1964, mientras que el resto son de la generación anterior. La lista de escritores contemplados incluye a personajes como Carlos Fuentes, Octavio Paz, Elena Poniatowska, que son considerados por la autora como intelectuales; a Luis González de Alba, Gilberto Guevara Niebla y Raúl Álvarez Garín, como testigos de los hechos; y a Sergio Aguayo, Héctor Aguilar Camín, Enrique Krauze, Soledad Loaeza, Luis Medina y Lorenzo Meyer como historiadores. La pregunta capital que Carmen Collado se hace es si las manifestaciones estudiantiles son realmente un punto de inflexión en la historia del siglo XX, según la versión de los antecitados.

El caso de Luis González de Alba es sumamente sugerente ya que, en su calidad de dirigente y miembro del Consejo General de Huelga, no asigna al 68 un lugar significativo en su obra Los días y los años y, de hecho, hace lo posible por evitar juicio alguno sobre el impacto que tuvo la matanza en el desarrollo político y social del país. Un caso contrario es el de Elena Poniatowska quien, en La noche 
de Tlatelolco. Testimonios de historia oral, alza la voz con tintes de denuncia contra el gobierno de Gustavo Díaz Ordaz por la violencia ejercida contra los jóvenes.

Más adelante, Carmen Collado apuntó que Carlos Fuentes consideró al movimiento estudiantil como una etapa definitiva en la historia nacional, de las mismas dimensiones que la Independencia o la Revolución por el impacto que tuvo en la transformación de las conciencias. A su vez, Meyer y Aguilar Camín afirmaron, en 1989, que se trató de un episodio más en el largo recorrido hacia la democracia, que estuvo abanderado por la clase media, y que dio salida a las inquietudes de los universitarios.

El estudio de la autora abarca hasta el siglo XXI, en donde ciertos intelectuales como Macario Schettino, escribieron que, lejos de ser una ruptura, los sucesos ocurridos en 1968 son parte de las múltiples expresiones discordantes con características antiautoritarias. Sin embargo, la mayoría de los escritores coindice en que desgastó las bases del régimen posrevolucionario — sobre todo el de la posguerra- y marcó un nuevo rumbo, tanto en el sistema político como en la constitución de un nuevo concepto de ciudadanía. La autora concluye que, tras este análisis la tendencia apunta a que, aún con el paso de los años, la mayoría exagera la importancia del 68 , por lo que se le atribuyen todos los cambios posteriores.

El tercer apartado fue elaborado por Rodrigo Laguarda, quien confesó que, al inicio de sus investigaciones, imaginó que 1968 era en punto axial en las transformaciones suscitadas en México, incluso en el caso que analizó, es decir, la lucha emprendida por la comunidad gay en pos de mayores libertades en la Ciudad de México. En efecto, la primera marcha del orgullo homosexual ocurrió el 2 de octubre de 1978, en donde un grupo de gays se unió a los contingentes que conmemoraban el décimo aniversario de la Matanza de Tlatelolco, sin embargo, la intención del autor es desmitificar la movilización estudiantil como el único elemento que explica las luchas subsiguientes.

Una de las principales virtudes del texto es que incrusta el caso mexicano en el contexto mundial, por lo que esboza las protestas acaecidas en Francia, Italia, la Primavera de Praga en Checoslovaquia, Japón y Estados Unidos. Asimismo, se vale de entrevistas a líderes de la comunidad gay mexicana para demostrar que sus recuerdos se habían acomodado, con el correr de los años, de tal forma que mitifican a 1968 como el génesis de su movimiento. Empero, incluso en las declaraciones de los interrogados que veían la lucha estudiantil de finales de los sesenta como el camino que llevó a mayores libertades sexuales, hay elementos que develan otros componentes que nada tiene que ver con la represión gubernamental contra estudiantes.

De hecho, el documento señala que, más allá del 68, uno de los principales catalizadores que permitieron la creación de una identidad gay fue la globalización. En efecto, la concreción de las comunidades homosexuales en ciudades como Nueva York y San Francisco jugaron un papel protagónico en la forma en que la sociedad concibió a dichos sectores. En la visión del autor, 
aquellos que vivieron el proceso de liberación sexual a partir de 1978, dan un peso exagerado a las manifestaciones registradas un decenio antes, y tal tergiversación responde al momento en que se realizaron las entrevistas, esto es, en el año 2000 cuando el Partido Revolucionario Institucional perdió la presidencia luego de administrar al país por décadas, y que el nuevo gobierno encabezado por Vicente Fox prometió una reforma al Estado, con el objetivo de poner fin a los vicios del viejo régimen.

Visto así, aquellas personas que no tuvieron ningún tipo de participación en las luchas de 1968 - la mayor parte de los sectores medios - siguieron sus vidas sin mayores sobresaltos, y sin haber sufrido transformaciones. Uno de los rasgos más destacados del trabajo hecho por Rodrigo Laguarda es que pone en evidencia la visión decimonónica de la historia, que pervive hasta nuestros días en la mente de mucha gente, en donde opera como una especie de juez y que, con el correr de los años, le da la razón a la justicia.

En el cuarto apartado, Graciela de Garay examinó la formación de los arquitectos de la Universidad Nacional Autónoma de México y la manera en que cambió su disciplina tras la Matanza de Tlatelolco. Esta propuesta funciona para alejarse del típico análisis político o social, y verlo desde la óptica artística. Su texto está basado en una serie de narrativas recogidas en el proyecto Historia oral de la Ciudad de México: testimonios de sus arquitectos y, con base en dichas fuentes, aseguró que las influencias internacionales —las luchas estudiantiles estadunidenses y europeas - son insuficientes para explicar las causas últimas de los movimientos locales.

En ese tenor, este capítulo acierta en explorar el mundo estudiantil en los años posteriores a 1968, pero no solo en la Ciudad de México. Por ejemplo, menciona a los alumnos de la Universidad Autónoma de Nuevo León quienes, en 1971, se manifestaron en contra de una ley orgánica que implicaba el ascenso de militares al puesto de rector de la institución. Asimismo, la originalidad del trabajo presentado por Graciela de Garay radica en que ve las consecuencias del movimiento del 68 en el mundo artístico, aun cuando ese no fue sido el propósito original de los contingentes.

Para llegar a tal puerto, analizó a la generación de arquitectos que estuvieron activos durante los sesenta, y que tenían en común el impacto de la Segunda Guerra Mundial en sus infancias. En los años previos a la Matanza de Tlatelolco, buscaron elementos teóricos que contribuyeran a consolidar su profesión en un momento en el que parecía que tales preceptos estaban desgastados. Dichas inquietudes se trasladaron a la Universidad Nacional, en donde los estudiantes que fueron testigos del 68, exigieron una renovación en los métodos de enseñanza, los cuales permanecían inalterados desde hacía mucho tiempo.

La autora logra explicar cómo las demandas del alumnado se toparon con la resistencia de las autoridades universitarias, que se unieron al fuerte sindicalismo de la institución y a la represión ejercida desde el gobierno, lo que desembocó en una corriente que exigió "arquitectura para el pueblo". En consecuencia, los luchadores consiguieron que se aprobara un nuevo plan de estudios, así como un 
autogobierno con fuerte incidencia en las decisiones que se tomaron en la facultad.

Es de llamar la atención la manera en que el texto explora las organizaciones estudiantiles acaecidas dentro de la máxima casa de estudios de México, en los años posteriores a 1968. Las secuelas que tuvo la lucha emprendida por los jóvenes arquitectos son notorias, puesto que, según Graciela de Garay, el reclamo por democratizar la enseñanza y poner los conocimientos al servicio del pueblo fueron la guía para los futuros arquitectos mexicanos, incluso latinoamericanos.

Finalmente, el último capítulo, cuyos autores son Javier Rico y Juan Salazar, está dedicado a la juventud, pensada más allá de las prácticas políticas y de su presencia en las universidades. Los académicos advierten que, al hablar de los jóvenes de 1968, se piensa en una fotografía instantánea en donde se condensa el trinomio joven-estudiante-rebelde, lo cual deja fuera a un amplio sector que no encaja en esta carctarización. De ahí se desprenden las preguntas, ¿quiénes son los que no están?, los que están, ¿son un grupo homogéneo?, ¿su experiencia vital se agota en el 68 ?

Para responder a los cuestionamientos, el texto da cuenta de los aspectos socioculturales de aquellos que se pueden catalogar "jóvenes" a finales de los sesenta. Si bien es un objetivo muy ambicioso por la dificultad que conlleva delimitar quiénes encajan en esa categoría y quiénes no, la propuesta resulta sensata al apostar por individuos de entre 14 y 29 años que compartieron más que la edad: el escrito incluye las prácticas culturales que eran comunes al grupo. Por tal motivo, Javier Rico y Juan Salazar analizaron películas, programas de televisión y, sobre todo, preferencias musicales compartidas. Aun así, advierten que se trata de un colectivo sumamente heterogéneo, que queda de manifiesto al auscultar las autobiografías de aquellos que divergen del común denominador.

Asimismo, es encomiable que en el trabajo queda asentada la incidencia del Estado posrevolucionario en múltiples aspectos de la vida social, pero que estaba lejos de ser una entidad omnipresente, rectora de la vida de todos los ciudadanos. En este caso, queda claro que el organismo gubernamental - el Instituto Nacional de la Juventud - pretendió encaminar a dicho sector hacia el progreso económico planteado por el Estado, pero numerosos estratos sociales, sobre todo de la clase media, entendieron esa "modernidad" como cultura libre, libertades sexuales y rock.

En ese sentido, los autores apuntaron que, si bien el sistema político tenía una visión vaga, puesto que entendió a la juventud como un cuerpo monolítico, el discurso emanado del movimiento estudiantil romantizó a quienes participaron en las protestas, y terminó siendo un discurso generalizador. En la realidad, las diferencias no solo se quedaron en el plano político, sino que alcanzaron al ámbito socioeconómico. La intención del trabajo es, entonces, buscar a los actores "vivos", es decir, hacer visible la cotidianeidad de aquellos que no salieron a la calle a gritar consignas. 
Es así como Javier Rico y Juan Salazar ponen en papel las vivencias de Javier Godínez, un joven solitario que se involucró en asuntos afines a la movilización, pero estuvo lejos de Tlatelolco durante los hechos violentos. También aparece la historia de Ernestina, enfermera que pasó la mayor parte de su vida trabajando y tenía poco tiempo para asuntos ajenos a lo laboral, aunque vio las movilizaciones de lejos. Por último, el texto refiere el caso de "El Chato", quien creció en un entorno violento, y vio afectada su formación académica por la imposibilidad de acceder a la UNAM.

El otro gran aporte es que los escritores incluyeron el aspecto demográfico en su investigación, es decir, presentaron tablas con datos elaborados con base en la información del Instituto Nacional de Estadística, Geografía e Informática. Es sugerente que la población total que tenía entre 14 y 29 años sumaba 12.34 millones, por lo que los estudiantes manifestados representaron una franca minoría.

En suma, el capítulo ve a la juventud desde distintas aristas para matizar la idea de que la rebeldía era el común denominador de todos ellos. Prueba de ello, aseguran los autores, es que muchos optaron por adherirse a las filas de la burocracia; por citar un ejemplo, el Instituto Mexicano del Seguro Social absorbió a un buen número de especialistas de la salud, que habían estudiado en universidades públicas durante los años más álgidos de las protestas.

El libro en su conjunto busca incentivar la discusión, pero entendida como un espacio para reflexiones constructivas y alejada de los juicios maniqueos o las sentencias negativas. Si bien es cierto que está pensado como un reto a los historiadores, también es una invitación a todo el público lector para repensar las grandes rupturas de su pasado. Es innegable que la obra deja muchos espacios sin abarcar, y quedan múltiples actores por descubrir, pero esto se debe a que está diseñada justo para eso: incitar a la comunidad académica en revisitar los lugares comunes y abrir el panorama de interpretación. Al final, como sugieren los autores, el problema no es que haya una sola versión de los hechos, sino que ésta permanezca incólume tras el correr de los años, y funja como obstáculo a nuevas explicaciones. 